\title{
Individual decisions drive the changes in movement patterns of ground beetles between forestry management types
}

\author{
Zoltán Elek $^{1,2}$ (D) Jana Růžičková ${ }^{1} \cdot$ Péter Ódor $^{3}$
}

Received: 4 March 2021 / Accepted: 25 May 2021 / Published online: 18 June 2021

(C) The Author(s) 2021

\begin{abstract}
Moving from one habitat to another, the dispersal of individuals has consequences for their conditions, population dynamics and gene flow. Our major motivation was to explore the effects of different forestry treatments, such as preparation (partial) cuts and clear cuts, on the selected population of the forest ground beetle, Carabus coriaceus (Coleoptera: Carabidae). We tagged six individuals (three males and three females) with small radio-transmitters and each was released in the treatment habitat core, at the edges and in the core of control forests respectively. The recorded trajectories were divided into two major movement phases: a random walk and a directional movement using hidden Markov models. Our results revealed that in the core zone of preparation cuts, the random walk and the directional movement were equally distributed in the trajectory. A clear directional movement was observed in the clear cuts suggesting the beetles moved directly toward the adjacent (control) forest interior. The trajectories at the edges of both treatments were dominated by the random walk and so for the controls. These results suggest that forest ground beetles can avoid the forestry treatments especially clear cuts, however edge habitats and (the studied) preparation cuts can mitigate the migration constraints due to their more favorable environmental conditions compared to clear cuts.
\end{abstract}

Keywords Ground beetles $\cdot$ Movement trajectories $\cdot$ Hidden Markov models $\cdot$ Radio-tracking $\cdot$ Oak-hornbeam forests

\section{Introduction}

In managed mature forests, ecological processes are characterized by frequent changes, resulting from either natural disturbances, such as storms and wildfires, or various silvicultural interventions that can partially control these natural processes or even attempt to mimic them (Sapke et al. 2016). Certain management types can create complex forest mosaics and establish new habitats, such as forest gaps or clear cuts, which might be beneficial for some organisms (Elek et al. 2018). Management can undoubtedly influence ecological processes as well as insect assemblages in forests (Christensen and Emborg 1996; Paillet

Zoltán Elek

zoltan.elek2@gmail.com

1 MTA-ELTE-MTM Ecology Research Group, Hungarian Academy of Sciences, c/o Biological Institute, Eötvös Loránd University, Pázmány Péter sétány 1/C, 1117 Budapest, Hungary

2 Hungarian Natural History Museum, Baross u. 13, 1088 Budapest, Hungary

3 MTA Centre for Ecological Research, Institute of Ecology and Botany, Vácrátót, Hungary et al. 2018), even though the conservation impacts of these changes remain a complex task. The European management shifts toward the so-called close-to-nature model to support biodiversity and the persistence of species requiring postdisturbance conditions (Kuuluvianen et al. 2012; Koivula et al. 2019). Such objectives are accomplished, for instance, by the maintenance of old-growth attributes (Pommerening and Murphy 2004; Bauhus et al. 2009) continuous cover forestry or retention forestry (Lindenmayer et al. 2012; Mori and Kitagawa 2014). These initiatives underline the fact that it is important to explore the interactions between various forestry treatments and the forest-dwelling organisms to unravel possible ecological consequences. Ground-dwelling carabids (Coleoptera: Carabidae) have a short lifespan, a higher position in the food web and give a complex response to changes in their abiotic and biotic environment (Lövei and Sunderland 1996) including a firm response to forest stand structural complexity at different temporal and spatial scales (Butterfield et al. 1995; Lövei and Sunderland 1996; Niemelä et al. 2007; Negro et al. 2017). Our previous study revealed that ground beetles, a group with moderate mobility, gave a weaker and somewhat less specific response manifesting in a general decline in abundance among several forest management types (Elek et al. 2018). This is presumably caused 
by the short-term response, which is explained by the loss of forest specialists due to treatments implementation (Niemelä et al. 2007; Elek et al. 2018). The large forest ground beetle, Carabus coriaceus L., 1758, sensitively reacts to forest management and it is predominantly associated with the uneven-aged (mostly beech) forest stands (du Bus de Warnaffe and Lebrun 2004). This species is considered as a forest species with constant occurrence and abundance in the oak-hornbeam zone of the Pilis Mountains, Hungary (Andorkó and Kádár 2006). Carabus coriaceus reproduces in autumn and overwintering as both, larvae and adult, with the highest activity in the autumn (Andorkó and Kádár 2006). The focus of forest ecology studies is at supraindividual level (Paillet et al. 2018) with their inevitable time constraints: the effects on populations and assemblages need several generations to unfold (Niemelä et al. 2007; Elek et al. 2018). Nevertheless, organisms can react to changing conditions in their habitats at lower organizational (individual or population) levels, including behavioral characteristics, which are more immediate (Parsons 1992). Although a suitable framework for collecting movement behavioral data at the individual level exists for decades, the majority of the published radio telemetry studies on insects focus on the methodological issues (Kissling et al. 2014). Only a few go further and study the movement characteristics over the total distance taken by the individuals (Rủžičková and Veselý 2016; Nergo et al. 2008, 2017). However, these studies did not quantify the distribution of the trajectory parameters such as step lengths and turning angles. Hitherto, there is a need for inferential methods that attempt to unravel relationships between factors driving movement, and predict them in quantitative terms. Hidden Markov models (HMMs) form a class of statistical models that have rapidly gained prominence in the movement ecology due to the fact that they are able to adapt complex structures that account for changes between unobservable systematic states in movement (McClintock et al. 2020). In our study, we aimed to explore and quantify the relationship between movement parameters and forest management types for ground beetle, C. coriaceus in temperate managed oakhornbeam forests in Hungary. We used radio telemetry to record the average speed of movement and time when beetles were active and trajectory profiles in different forestry treatments, such as preparation cuts and clear cuts, and their control plots. In addition, we intended to decrypt distinct movement stages from trajectories and estimate their variation between individuals and treatments.

\section{Materials and methods}

\section{Site description and study design}

The study area located in the Pilis Mountains $\left(47^{\circ} 40^{\prime} \mathrm{N}\right.$, $\left.18^{\circ} 54^{\prime} \mathrm{E}\right)$, Northern part of Hungary. The elevation is 370 $470 \mathrm{~m}$ a.s.l. with the annual mean temperature is $9.0-9.5^{\circ} \mathrm{C}$ and mean annual precipitation is $600-650 \mathrm{~mm}$ (Dövényi 2010). The experiment was implemented in a mature ( 80 years old), 40 ha sized, managed sessile oak-hornbeam forest stand (Natura 2000 code: 91G0) (European Commission 1992). The stand has been managed by shelterwood silvicultural system resulting in structurally homogeneous conditions. The canopy layer was dominated by sessile oak (Quercus petraea (Matt.) Liebl.) with the mean tree height $21 \mathrm{~m}$ and the mean diameter (at breast height) $28 \mathrm{~cm}$. Subordinate species of this layer were turkey oak (Quercus cerris L.), beech (Fagus sylvatica L.) and wild cherry (Prunus avium L.). Hornbeam (Carpinus betulus L.) formed secondary $11-\mathrm{m}$ tall canopy layer with manna ash (Fraxinus ornus L.) appeared as a subordinate species. The shrub layer was scarce; the understory cover was ca. $30 \%$, consisting mainly of mesic forest plants, dominated by Carex pilosa Scop. and Melica uniflora L.

Our study was the part of the long-term Pilis Forestry System Experiment (https://piliskiserlet.ecolres.hu/en/node/ 1) where four forestry treatments including their control (C) were established in 2014 with six-replicate blocks to explore the major effect of various treatments on forest organisms, such as plants, enchytraeids worms, spiders and ground beetles (further details are available in Elek et al. 2018). Two of the four implemented treatments, representing characteristic stages of rotation forestry system, were used for radiotracking of ground beetles: (1) clear-cutting (CC), a 0.5 ha circular clear-cutting area of $80 \mathrm{~m}$ diameter, surrounded by closed canopy stand; (2) preparation cutting (P), $30 \%$ of the total basal area of the dominant tree layer and the whole secondary tree layer was removed in a spatially uniform way in a circle of $80 \mathrm{~m}$ diameter.

\section{Radio-tracking of ground beetles}

Six individuals (three males and three females, collected in the study area by unbaited pitfall traps) of the flightless C. coriaceus were mounted with VHF radio tags: model "PicoPip" manufactured by Biotrack Ltd, Wareham, England (www.biotrack.co.uk). The maximum weight of the tags was $0.29 \mathrm{~g}$ with the individual frequencies between 150 . 325 and $150.915 \mathrm{MHz}$ and the battery (type Ag 337) life-span of 8 days. Tags were fixed on the top of the beetle's elytra by cyanoacrylate glue (Loctite PowerFlex gel) with the antenna $(5 \mathrm{~cm})$ directed backward (Fig. 1). Although Negro et al. $(2008,2017)$ revealed that this adhesive was more appropriate than the silicone gel (Riecken and Raths 1996), we used this gel for sealing the joint and make it waterproof. Individuals were kept for $24 \mathrm{~h}$ in a dark box before their release and were fed ad libitum. Two of the tagged beetles were released in the treatment cores ( $\mathrm{CC}$ or $\mathrm{P})$, two at their edges and the last two in the adjacent control forest stand (C). Each beetle's movement was tracked every four hours for five days in autumn 2018. During the experiment, we recorded the movement 
parameters for each beetle including their exact geolocation (fix) by GPS device (Garmin Dakota 20, in WGS84 coordinate reference system) and the absolute turning angle (i.e. angle towards a fixed point, such as magnetic north) and the distance from the previous location to correct potential GPS error. Fixes with the observed movement were considered as active, while the fixes without activity as passive. The proportion of the active time was calculated as a ratio between active and passive fixes. For each beetle and relocation, we also recorded (Basetech model no. $1065 \mathrm{H}$, Conrad Electronic $\mathrm{SE}$, Germany) the ground and air temperature (in Celsius degree), relative humidity (as percent) and air pressure (in $\mathrm{mmHg}$ ) as potential abiotic covariates with the exact date (year, month, day, hour, minute) that may influence beetles' activity (e.g. Thiele 1977; Negro et al. 2017). We further investigated the potential influence of the tag's weight on beetles, and found that body/tag mass ratio was $14 \%$ in average (Table 1) which is far below as it was in previous findings for the same species (50\% in Riecken and Raths 1996). Although there is no direct suggestion for body/tag mass ratio for walking insect, a recent study suggests $23-33 \%$ limits for these thresholds for flying species (Batsleer et al. 2020), thus we believe that tags used in this study apparently did not bias beetles' movement. Although we tagged only six individuals, we found that the quality of the data is suitable to draw relevant consequences. Kissling et al. (2014), Růžičková and Veselý $(2016,2018)$ and Liégeois et al. (2016) proved that the consistency of the individuals responses are not related to the samples sizes due to the individual behavior of walking insects. We have selected the target organism and forestry treatments based on our previous findings (Elek et al. 2018), where we demonstrated that these treatment types have the most adverse effect on the assemblage composition of ground beetles. In the clear-cuts (CC), we found the loss of forest specialists, including $C$. coriaceus, while the least adverse effects were detected in preparation cuts $(\mathrm{P})$.

\section{Data analysis}

Although the statistical methods used in movement ecology are still increasing, the broad analysis of movement data is still a challenge (Michelot et al. 2016; Patterson et al. 2017). Among the vast variety of models that have been used to analyze movement data, the hidden Markov models (HMM) have a distinguished attention in recent years due to their appealing combination of model flexibility, clear interpretability and computational tractability (Michelot et al. 2016; Patterson et al. 2017). The HMM models are part of an extended family of state-switching models focusing on the decomposition of the movement process into distinct underlying states. This approach matches our intention to prove that most animals' movement is driven by switches in behavioral modes. In the models, we defined two distinctive stages of beetles' movement based on the distance (as a step length in meters) and the direction (as a turning angle in degrees) between two movement steps in time. (1) Random walk is defined as the high proportion of (sharp) turns during the movement, the distance taken is relatively small (turning angles > step length) and no explicit direction can be identified (Baars 1979; Kareiva and Shigesada 1983). The random walk is a good proxy for animal's foraging behavior (Thiele 1977; Kareiva and Shigesada 1983; Wallin and Ekbom 1988) indicating that the individual uses a habitat for living. (2) Directional movement can be described by the long distances taken between two movement steps with relatively flat turning angles and thus an explicit direction can be identified (turning angles $<$ step length, sensu Dray et al. 2010). This pattern is a neat proxy for migration from a habitat to another (Kareiva and Shigesada 1983; Wallin and Ekbom 1988). The applied HMM model based on a complete pooling, where all individual are assumed to share the same movement parameters (Langrock et al. 2012). For modeling, the initial parameters of the step length (distances) with gamma distribution were set as $\mu=\mathrm{c}(0.001,0.01)$ for random walk $(1 \mathrm{~m} \mathrm{limit} \pm 0.11 \mathrm{~m})$ and directional movement $(10 \mathrm{~m}$ limit $\pm 0.5 \mathrm{~m})$, respectively; while, the von Mises distribution was used to model the turning angles with initial parameters $K=c(1,1)$ for the same stages as above (Michelot et al. 2016) suggesting that turning angels have the same initial parameters for both states. The detailed model parametrization and formulation with explanation is available in the Online resource 1: Table S1. Bayesian correlation test (Makowski et al. 2019) based on Bayes factor (BF) as continuous relative evidence was used to confirm the probability for the relationship between activity density data (for C. coriaceus abundance data from Elek et al. 2018) and animals' activity described by the distance covered between the two movement steps in particular treatment types (Online resource 1: Table S2). This approach provides a quantitative comparison, whether the movement profiles are similar between treatment types. The rules applied to $\mathrm{BF}$ ratios were given by a previous finding (Raftery 1995), where $\mathrm{BF}=1$ no evidence; $1<\mathrm{BF}<=3$ - weak; $3<\mathrm{BF}<=20$ - positive; 20 $<\mathrm{BF}<=150-$ strong and $\mathrm{BF}>150$ designate a very strong correlation. All the analyses were implemented in R 3.6.1 (R Core Team 2020), using package 'moveHMM' (Michelot et al. 2016) for trajectories and package 'BayesFactor' (v0.9.12-4.2, Morey and Rouder 2018) for Bayesian correlation tests.

\section{Results}

\section{Movement characteristics of the individuals}

During the experiment, we had 30 potential record slots (fix) for each individual due to sampling protocol, however, the 
Fig. 1 A tagged female of Carabus coriaceus (on the top right corner) and a relocated beetle (on the top left corner) with a radio tag hidden under the leaf litter and an aerial photo (on the bottom) about the study sites including the point of 1 st release for each beetle Pilis Mountains, Hungary. Numbers corresponds to the beetles' ID as given in Table 1
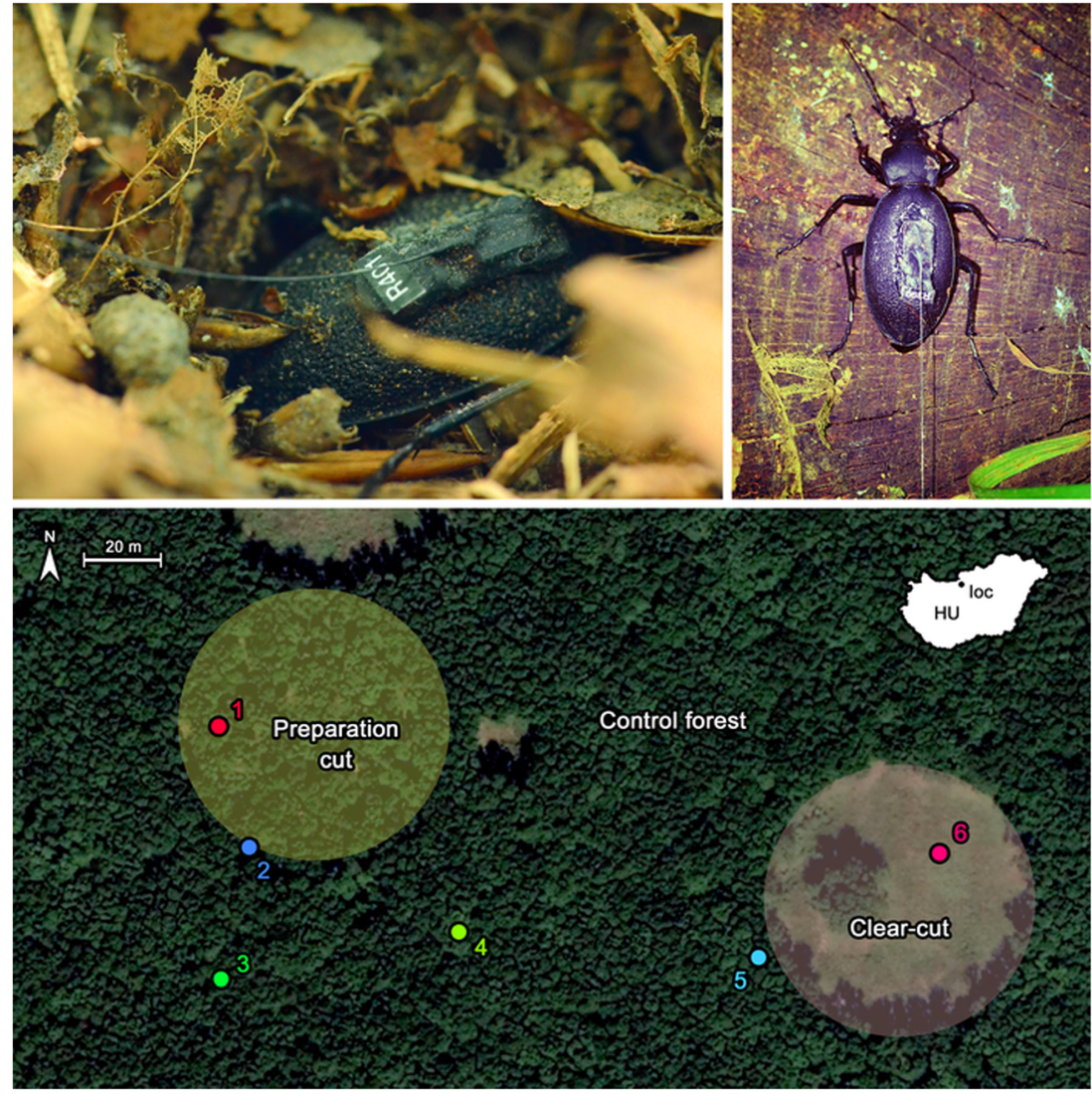

number of recorded fixes were within the range 27-29 fixes, except for one male where the total number of fixes was 18 , thus we assumed that the collected number of fixes are adequate (more than 10 fixes/trajectory as suggested by Turchin et al. 1991.) for further analyses (see details in Table 2). In addition, each individual has more passive fixes recorded than active ones. We found that the signal of beetle no. 4 (RP) has been lost at the end of the surveillance period (00:00 am at 23/ 09/2018), due to predation likely by bats. Thus, the last step has been considered as biased, since we cannot exclude that this step whether is taken by the beetle itself or by its predator. Nevertheless, specimens showed much higher activities during the night than daytime (Fig. 2). The correlation test for the movement parameters such as active step lengths, turning angles and the most influential environmental variables revealed that the ground and air temperature are the most influential on the beetles' step length suggesting a decline in movement activity over 20 degrees Celsius (Fig. 3). However this relationship can be biased by three outliers, thus we have tested the absolute differences in temperatures on step length and found no significant effect on movement (Fig. 3).

The complete pooling HMM model gave the maximum log-likelihood, 34.773 with approximately normally distributed pseudo-residuals for the overall fit, thus we assumed that the model parametrization was accurate enough (Online resource 1: Table S1). On average, the majority of the step
Table 1 Beetles' initial body mass without fixed transmitter, ratio of body and tag mass including other technical details for radio tags, such as factory serial ID and specific frequency used during the experiment

\begin{tabular}{llllllll}
\hline ID & Names & Sex & $\begin{array}{l}\text { Tag serial } \\
\text { no. }\end{array}$ & $\begin{array}{l}\text { Tag weight } \\
(\mathrm{g})\end{array}$ & $\begin{array}{l}\text { Frequency } \\
(\mathrm{MHz})\end{array}$ & $\begin{array}{l}\text { Body mass } \\
(\mathrm{g})\end{array}$ & $\begin{array}{l}\text { Body \& tag mass } \\
\text { ratio (\%) }\end{array}$ \\
\hline 1 & TMB & Female & R398 & 0.29 & 150.325 & 2.4579 & 11.80 \\
2 & LG & Female & R399 & 0.29 & 150.396 & 2.3737 & 12.22 \\
3 & MT & Female & R400 & 0.29 & 150.467 & 1.954 & 14.84 \\
4 & RP & Male & R401 & 0.29 & 150.514 & 1.8487 & 15.69 \\
5 & DM & Male & R402 & 0.29 & 150.554 & 1.8329 & 15.82 \\
6 & KH & Male & R403 & 0.29 & 150.915 & 1.6994 & 17.06 \\
\hline
\end{tabular}

The column "names" designate the nicknames of the beetles which is identical the ones used on Figs. 4 and 6 
lengths were less than $10 \mathrm{~m}$, but 20 - or $30 \mathrm{~m}$-distances also occurred with least frequency (Fig. 4; Online resource 1: Figure S1). The density of turning angles described well the two predefined movement states, negative turning angle (mean: -1.89 radians) are associated with random walk, while the positive turning angle (mean: 0.24 radians) we typical for directional movement (Online resource 1: Figure S1). The transition probability for random to directional movement state $(1 \rightarrow 2)$ was $6.5 \%$, while the probability for opposite state switching $(2 \rightarrow 1)$ was $90 \%$. The proportion of the random walk and the directional movement for step length revealed that all movements were dominated by the random walk especially in the treatment cores (Fig. 4; Online resource 1: Figure S2; Online resource 2), while at the treatment edges and control were dominated by high transition probability from the directional movement to the random walk. In addition, we also observed a consequent inactive phase in movement activities for $5-10 \mathrm{~h}$ for all beetles. Both treatments were used only temporarily, and beetles were faster and more active there than in control forest (mean speed: $0.56 \mathrm{~m} / \mathrm{h}$ in $\mathrm{P}$, $0.33 \mathrm{~m} / \mathrm{h}$ in CC, and $0.26 \mathrm{~m} / \mathrm{h}$ in C; active time: $38 \%$ in $\mathrm{P}$, $21 \%$ in $\mathrm{CC}$ and $18 \%$ in C). Moreover, they left preparation cuts, as well as clear-cuts within a few days. In addition, the weak positive correlation was confirmed (Fig. 5; Online resource 1: Table S2), that treatments were characterized by high activity density values and long distances taken by tagged individuals. The profiles of each trajectory in both treatments were characterized by uneven angles and relatively long movement steps, indicating a definite walking direction toward the treatment edge, even though we observed the opposite pattern at the edges and control plots, where the random

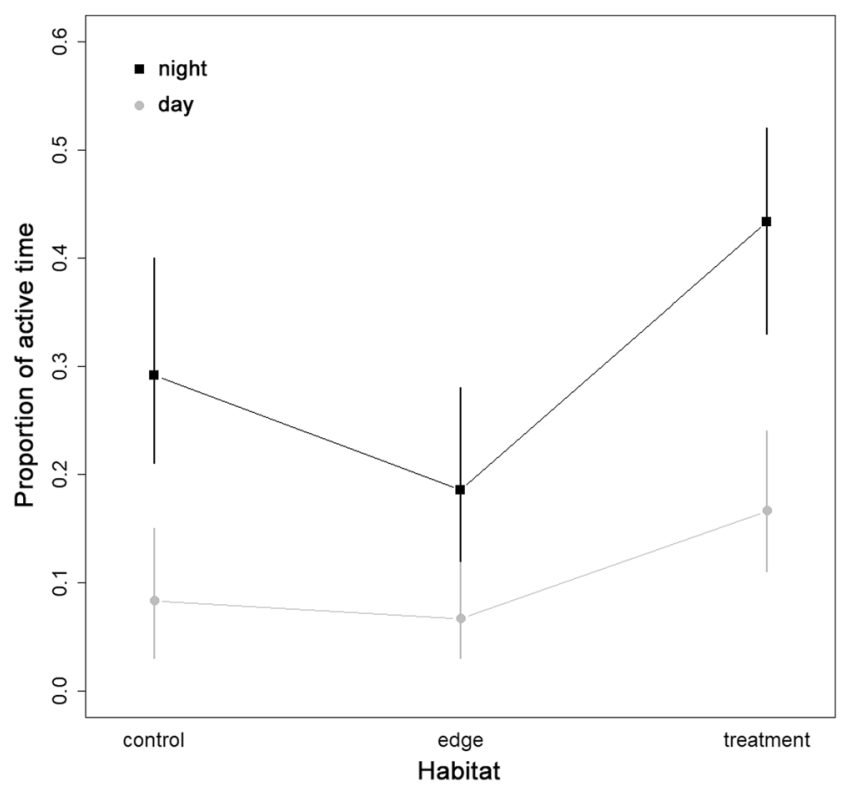

Fig. 2 The diurnal activity pattern of beetles (time with active movement during the experiment with mean and standard deviation) per different forestry treatments walk characterized the animals' movement (Fig. 6; Online resource 1: Figure S2; Online resource 2).

\section{Discussion}

Our study revealed that the radio-tagged beetles utilize the various forest management types regardless of the individual variation in movement. The two-state HMMs have given a quantitative assumption that clear-cuts is characterized by the directional movement, while the random walk component was mostly used by the beetles in the more closed forest stands including preparation cuts, its edges as well as adjacent controls. This underlines the adverse effect of certain forestry treatments on animal behavior, especially on movement patterns; the beetles escape from these sites after a few days of their release. In addition, we also observed that there is a nomovement phase in all trajectories last for ca. quarter of a day.

\section{Animal movement towards habitat use}

For many arthropods including ground beetles, the soil surface, "as a groundspace", provides habitat for a substantial part of their lives. It is essential for foraging, sheltering and migration (Vinatier et al. 2010; Hüppop et al. 2020). The "groundspace" is an acting scene for estimating the habitat utilization of ground-dwelling arthropods which is usually described by community-level measures, such as activity density or species richness, found in a particular habitat type, although the behavioral responses at the individual level providing more rapid feedback on the habitat use (Vinatier et al. 2010; Negro et al. 2017). There is a consensus that forest ground beetles tended to forage during the night (Thiele 1977), our results also proved that the majority of the active movement happened in nighttime (Negro et al. 2008, 2017). It is an important clue, since the movement cannot be biased by the interference of daytime active forest-dwelling arthropods in the same habitat such as dung, rove and saproxylic beetles or spiders. This underlines the fact that there is a sophisticated spatio-temporal arrangement in functional skills in forest ecosystem to avoid density-dependent competition among species due to niche overlap (Didham et al. 1996). The frequency and the length of the active movement steps suggest that the individual have left the clear-cuts immediately and the trajectory is characterized by a few long steps with definite direction toward the adjacent forest interior. This is similar to Negro et al. (2017) where the same pattern was detected for Carabus olympiae Sella, 1855 in strip cuts (clear-cutting in a line) suggesting that forest carabids emerge from a habitat where the canopy has opened. Although the studied individuals have left the treatment core habitats quite quickly, the random walk characterized by short and frequent movement steps in the preparation cuts assuming that foraging behavior 


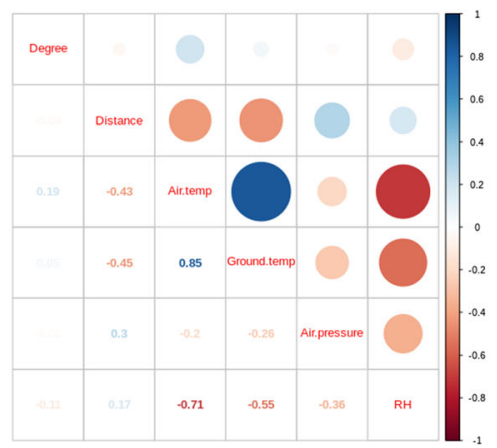

$F=7.32, d f=1,29, p=0.01$

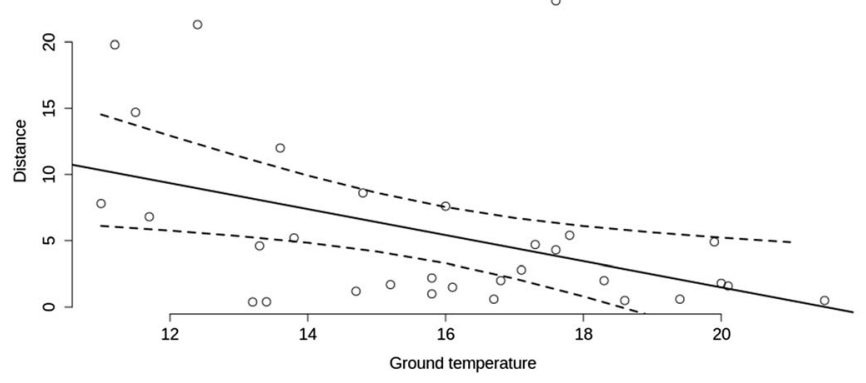

Fig. 3 The overview of the Spearman's rank correlation test for exploring the relationship between movement parameters, step lengths (Distance, only active steps are considered) and turning angles (Degree) and the most influential environmental variables such as air and ground
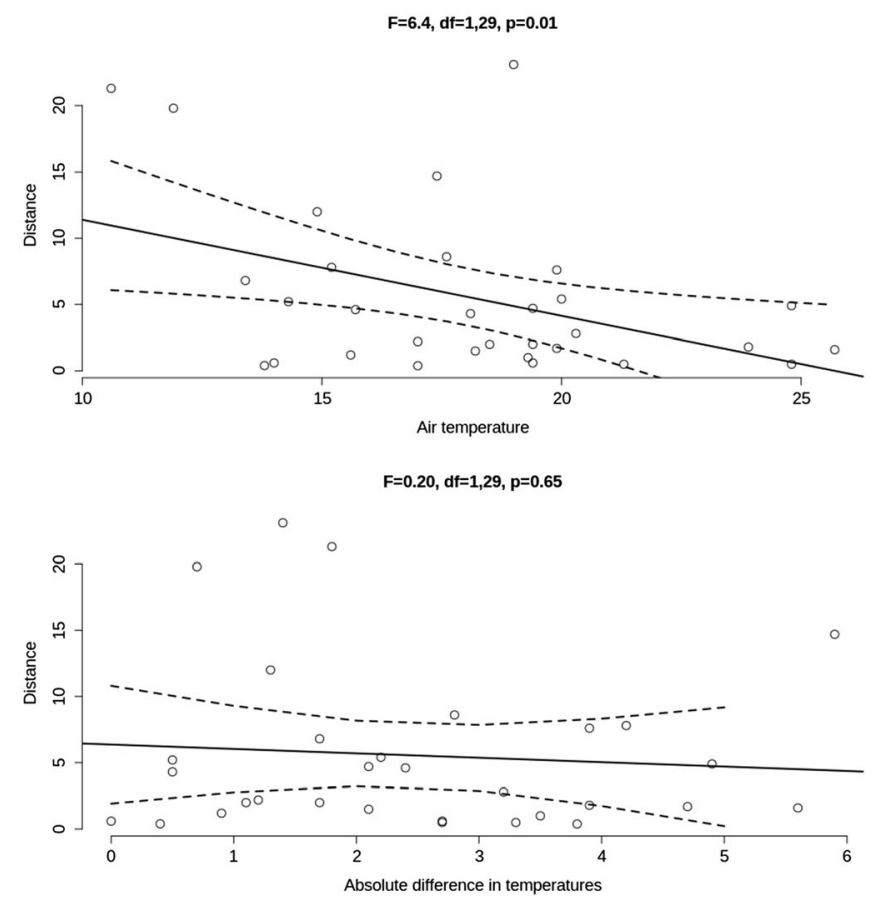

temperature, air pressure and relative humidity of the air $(\mathrm{RH})$. The effects of temperatures and their absolute differences are visited on the separate graph panels; the $95 \% \mathrm{CI}$ is based on the linear regression (output given on the top of each panel)

straight-line movement rate was one of the first measures for insect movement in relation to a body size (Lövei and Sunderland 1996). Large carabids, such as C. coriaceus, usually cover daily larger distances than smaller species likely due to their higher daily food requirement linked to their size ((Lövei and Sunderland 1996, Riecken and Raths 1996). Nevertheless, the identification of species groups is often performed to develop generalizations about the ecological movement characteristics of the woodland arthropods. The
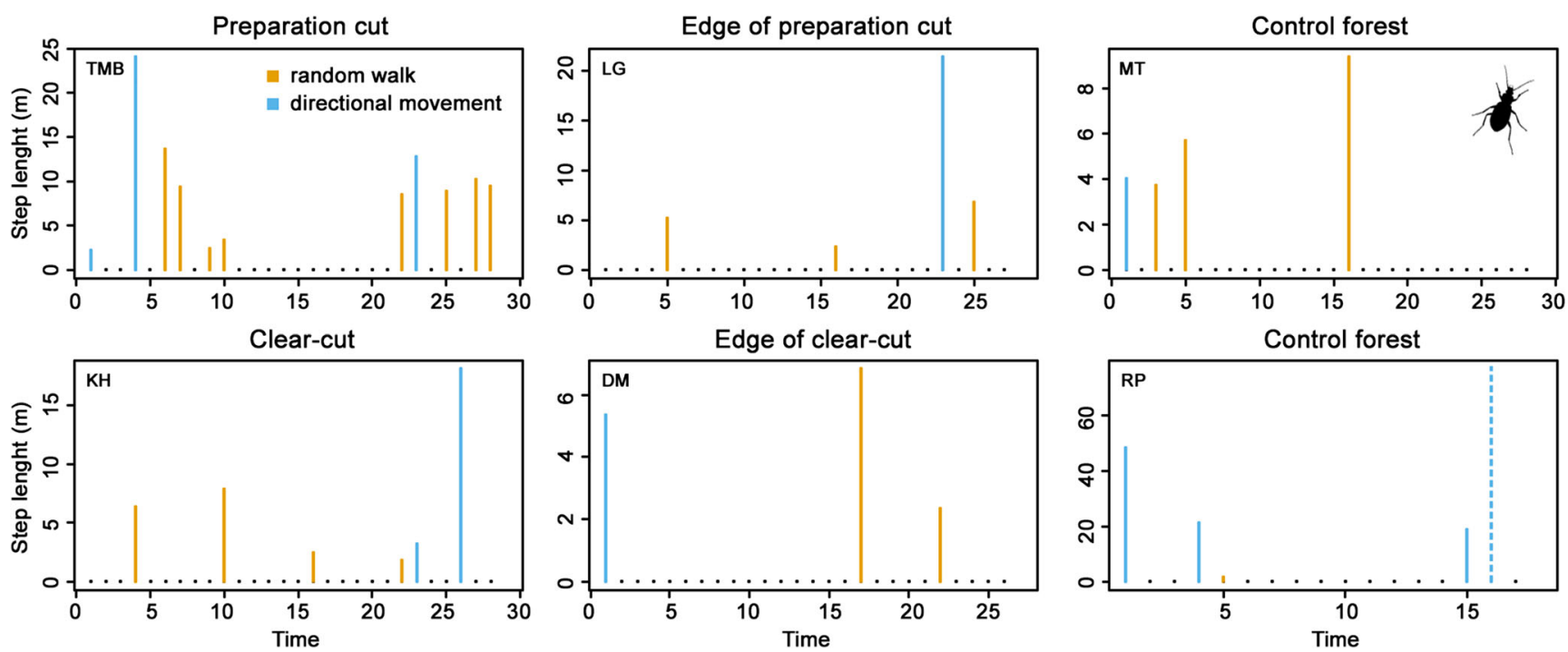

Fig. 4 Distribution of active (bars) and passive (dots) steps and their length in time between forestry treatments. For beetle "RP", the last detected step was considered as biased (movement after bat predation) and designated as a dashed line 


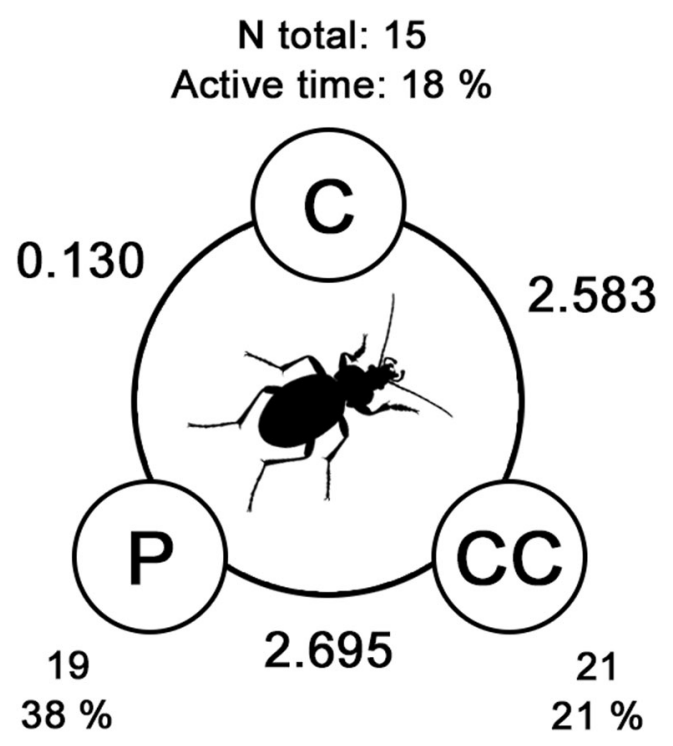

Fig. 5 Strength of evidence by Bayes factors for relationship between activity density and treatment types with the corresponding total abundance and active time in percent. The treatments are control (C), clear-cutting $(\mathrm{CC})$ and preparation cutting $(\mathrm{P})$

behavior of invertebrates, or leading to general recommendations in relation to conservation management (Lövei and Sunderland 1996; Brouwers and Newton, 2009; Viantier et al. 2010). Common approaches to categorize, mostly carabid, species include the degree of habitat specialization and physical traits, such as dispersal ability. Grouping ground beetles based on their mobility has been attempted in a long-term monitoring of heathlands in the Netherlands (Den Boer 1990a, b). This study revealed that this group was distinct in terms of dispersal ability and habitat occurrence (Den Boer 1990b). Heatland carabids could be categorized as species with low dispersal power inhabiting stable habitat vs. species with high power of dispersal inhabiting unstable habitat (Den Boer 1990a, b). In relation to forest carabids, these categories can be equivalent to behavior strategies in movement, such as migratory behavior, appears in unstable habitat (i.e. open canopy layer in clear cuts) whilst the random walk can be a proxy for designating stable habitats such as forest stands with closed canopy in preparation cuts and controls (Růžičková and Veselý 2016, 2018). In addition, our study underlines that different woodlands require different degrees of habitat connectivity for beetles, the trajectories in the treatment edges were not different from the control ones, suggesting that edges are so complex habitats and can be a lifeboat for forest specialist after forest management (Chiasson and Moreau 2020).

\section{Movement vs. community measures}

One of the most common measures for arthropod assemblages to estimate activity density defined as the number of catches in relation to activity. Therefore this measure can be considered as a reflection of animal movement since the higher activity of the individuals will lead to the higher catches of those in a trap. Although this linear relationship seems evident at the first sight, the movement attributes such as step length, frequency and turning angle can bias this correlation (Grüm 1971a, b). We found that beetles were more active in preparation and clear cuts than in controls, while their abundance seems independent from their activity. The community-level measures estimated differently the individuals' activity, and can be biased by the species identity and their functional role in forest ecosystems (Brouwers and Newton 2009). Therefore, studying animal movement is crucial for understanding habitat utilization of forest specialist carabids in the context of metacommunity issues to identify the keys elements for conservation actions (Grüm 1971a, b; Chiasson and Moreau 2020). Our study proved an important behavioral aspect of carabids movement, the individuals kept a quarter of the day lag in their movement regardless of utilized habitat types. A similar pattern was revealed for C. coriaceus in a previous study (Riecken and Raths 1996), where there was a 12-hour period of no activity occurred regularly for all tagged individuals in grassland-forest strip ecosystems in Germany. Previous studies (Ferrante et al. 2014; Fukuda and Konuma 2019) showed that carabids consist of a substantial part of the prey repertoire of several forest-dwelling birds and mammals. Thus we suggest that any time lag in animal movement trajectories can act as direct evidence for the avoidance of native predators, although the predation pressure can be speciesspecific (sensu lato Eötvös et al. 2020).

Table 2 Movement characteristics of the radio-tagged individuals of C. coriaceus in the Pilis Mountains, Hungary

\begin{tabular}{|c|c|c|c|c|c|c|c|c|c|}
\hline ID & Names & Sex & Treatment type & Locality & Mean speed $(\mathrm{m} / \mathrm{h})$ & Total distance $(\mathrm{m})$ & Fixes active & Fixes passive & Total fixes \\
\hline 1 & TMB & Female & Preparation cut & Treatment core & 0.91 & 105.3 & 11 & 18 & 29 \\
\hline 2 & $\mathrm{LG}$ & Female & Preparation cut & Edge & 0.32 & 35.9 & 4 & 24 & 28 \\
\hline 3 & MT & Female & Preparation cut & Control & 0.19 & 22.9 & 4 & 25 & 29 \\
\hline 4 & $\mathrm{RP}$ & Male & Clear cut & Control & 2.30 & 89.2 & 4 & 14 & 18 \\
\hline 5 & $\mathrm{DM}$ & Male & Clear cut & Edge & 0.13 & 14.6 & 3 & 24 & 27 \\
\hline 6 & $\mathrm{KH}$ & Male & Clear cut & Treatment core & 0.34 & 40.0 & 6 & 23 & 29 \\
\hline
\end{tabular}

The column "names" designate the nicknames of the beetles which is identical the ones used on Figs. 4 and 6 

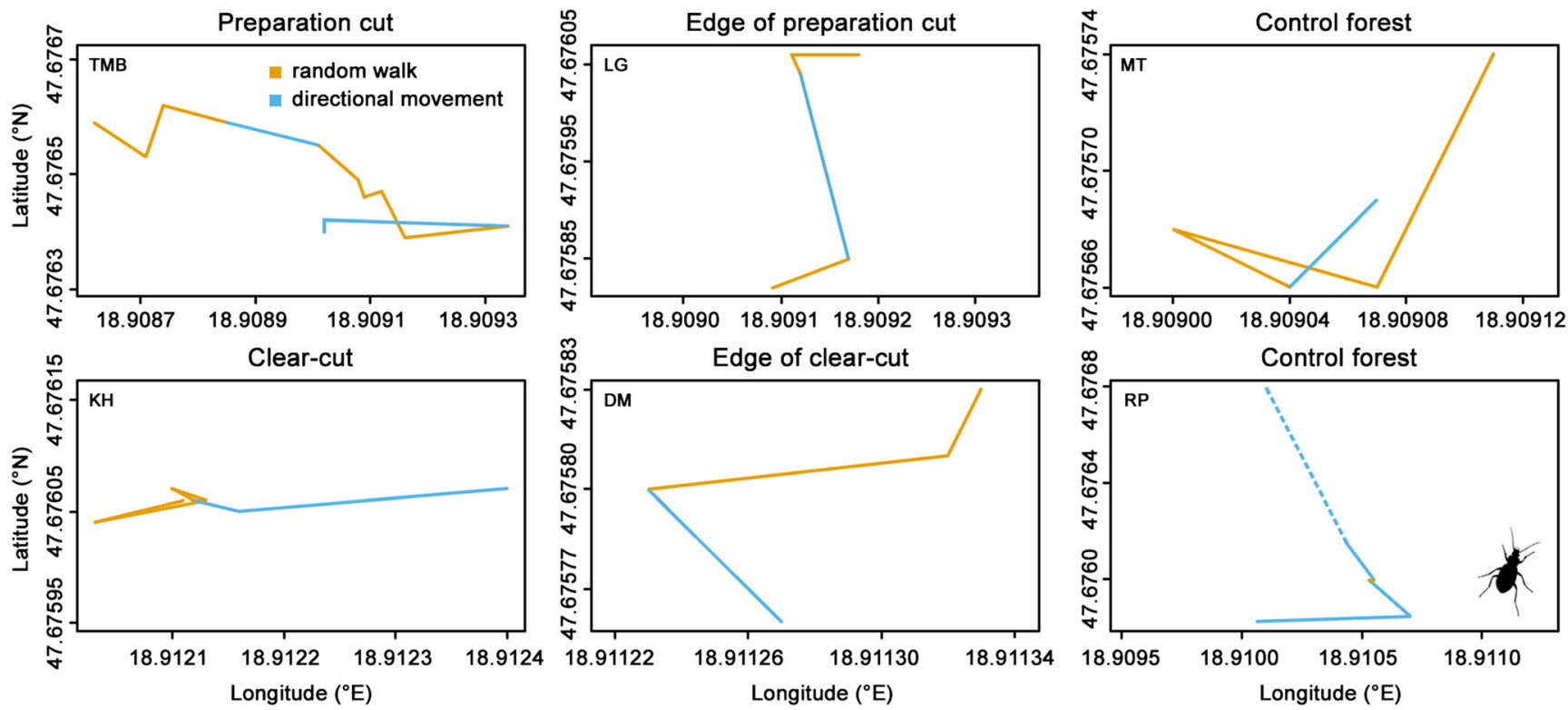

Fig. 6 The individual trajectories of the studied specimens in different forestry treatments, Pilis Mountains, Hungary. The yellow segments are designating the random walks, while the blues ones are for directional movements. For beetle "RP", the last segment was considered as biased one due to signal lost and designated as a dashed line

\section{Conclusions}

It is still a common debate how to use animal movement trajectories in species conservation action plans. As our results revealed that the movement at the individual level cannot be directly connected with the community level, thus the generalization for effective conservation is rather unfolded. Therefore, there is a demand to explore and adapt the existing analytical tools in movement ecology including arthropods, although the approach can be biased by spatial constraints of insect movement. Our findings showed that there is a standard and quantitative way to analyze the insect movement trajectories suggesting that opening in forests can be a sink habitat for predominantly forest carabids and the surrounding closed stands are the key for the recolonization of the open areas. Hitherto, we also found that the regular time lag with no activity in trajectories can be a key element for survival due to the avoidance of predators. This is also important to consider for planning further radio-tracking studies on ground-dwelling predators, such as carabids. This feature can be also a frontier to plan further studies toward predator-prey co-evolutionary adaption based on individual movements. Although the methodological aspects of movement ecology develop progressively in relation to equipment and statistical tools, the insect movement studies have still remained rather method-centered, only a few studies address any ecological issue being tested by telemetry. This approach can be ideal for rapid conservation assessments to provide clues for direct, evidence-based conservation actions.
Supplementary Information The online version contains supplementary material available at https://doi.org/10.1007/s11756-021-00805-x.

Acknowledgements Authors thank for the Pilis Parkerdő Ltd. (Péter Csépányi, Viktor Farkas, Gábor Szenthe, László Simon) for the maintenance of the experimental site.

Authors' contributions ZE conceived the ideas and designed the methodology; ZE, JR collected the data; ZE analyzed the data with input from other authors; ZE, JR, PO led the writing of the manuscript.

Funding The study was supported by Hungarian Research Fund (NKFIH-K 111887, 128441) and by the Hungarian Academy of Sciences (MTA KEP, Ecology for Society project). Open access funding provided by Eötvös Loránd University.

\section{Declarations}

Conflict of interest The authors declare they have no conflict of interests.

Ethics statement The authors declare that they have no financial and personal relationships with other people or organizations that can inappropriately influence their work. All data and material can be available from the authors.

The direct observation of carabids individuals in this study were noninvasive, all research within this project were conducted under the license from the respective Hungarian authority (Közép-Duna-Völgyi Környezetvédelmi és Természetvédelmi Felügyelőség KTF:30362-3/ 2014).

Open Access This article is licensed under a Creative Commons Attribution 4.0 International License, which permits use, sharing, adaptation, distribution and reproduction in any medium or format, as long as 
you give appropriate credit to the original author(s) and the source, provide a link to the Creative Commons licence, and indicate if changes were made. The images or other third party material in this article are included in the article's Creative Commons licence, unless indicated otherwise in a credit line to the material. If material is not included in the article's Creative Commons licence and your intended use is not permitted by statutory regulation or exceeds the permitted use, you will need to obtain permission directly from the copyright holder. To view a copy of this licence, visit http://creativecommons.org/licenses/by/4.0/.

\section{References}

Andorkó R, Kádár F (2006) Carabid beetles (Coleoptera: Carabidae) communities in a woodland habitat in Hungary. Entomol Fenn 17: 221-228. https://doi.org/10.33338/ef.84334

Baars MA (1979) Patterns of movements of radioactive carabid beetles. Oecologia 44:125-140. https://doi.org/10.1007/BF00346411

Batsleer F, Bonte D, Dekeukeleire D, Goossens S, Poelmans W, Van der Cruyssen E, Maes D, Vandegehuchte ML (2020) The neglected impact of tracking devices on terrestrial arthropods. Methods Ecol Evol 11:350-361. https://doi.org/10.1111/2041-210X.13356

Bauhus J, Puettmann K, Messier C (2009) Silviculture for old-growth attributes. For Ecol Manage 258:525-537. https://doi.org/10.1016/ j.foreco.2009.01.053

Brouwers NC, Newton AC (2009) Movement rates of woodland invertebrates: A systematic review of empirical evidence. Insect Conserv Divers 2:10-22. https://doi.org/10.1111/j.1752-4598.2008.00041.x

Butterfield J, Luff MLL, Baines M, Eyre MDD (1995) Carabid beetle communities as indicators of conservation potential in upland forests. For Ecol Manage 79:63-77. https://doi.org/10.1016/03781127(95)03620-2

Chiasson B, Moreau G (2020) Assessing the lifeboat effect of retention forestry using flying beetle assemblages. For Ecol Manage 118784. https://doi.org/10.1016/j.foreco.2020.118784

Christensen M, Emborg J (1996) Biodiversity in natural versus managed forest in Denmark. For Ecol Manage 85:47-51. https://doi.org/10. 1016/S0378-1127(96)03749-8

Den Boer PJ (1990a) Density limits and survival of local populations in 64 carabid species with different powers of dispersal. J Evol Biol 3: 19-48. https://doi.org/10.1046/j.1420-9101.1990.3010019.x

Den Boer PJ (1990b) The survival value of dispersal in terrestrial arthropods. Biol Conserv 54:175-192. https://doi.org/10.1016/00063207(90)90050-Y

Didham RK, Ghazoul J, Storck NE, Davis AJ (1996) Insects in fragmeneted forests: a functional approach. Trends Ecol Evol 11: 255-260. https://doi.org/10.1016/0169-5347(96)20047-3

Dövényi Z (2010) Magyarország kistájainak katasztere. Magyar Földtani Intézet, Budapest

Dray S, Royer-Carenzi M, Calenge C (2010) The exploratory analysis of autocorrelation in animal-movement studies. Restor Ecol 25:673681. https://doi.org/10.1007/s11284-010-0701-7

du Bus de Warnaffe G, Lebrun P (2004) Effects of forest management on carabid beetles in Belgium: implications for biodiversity conservation. Biol Conserv 118:219-234. https://doi.org/10.1016/j.biocon. 2003.08.015

Elek Z, Kovács B, Aszalós R, Boros G, Samu F, Tinya F, Ódor P (2018) Taxon-specific responses to different forestry treatments in a temperate forest. Sci Rep 8:16990. https://doi.org/10.1038/s41598-01835159-z

Eötvös CB, Lövei GL, Magura T (2020) Predation pressure on sentinel insect prey along a riverside urbanization gradient in Hungary. Insects 11:97. https://doi.org/10.3390/insects 11020097

European Commission (1992) Council Directive 92/43/EEC of 21 May 1992 on the Conservation of Natural Habitats and of Wild
Fauna and Flora. https://www.ec.europa.eu/environment/nature/ leg-islation/habitatsdirective/index en.htm/.Accessed 18 Dec 2020

Ferrante M, Lo Cacciato A, Lövei GL̄ (2014) Quantifying predation pressure along an urbanisation gradient in Denmark using artificial caterpillars. Eur J Entomol 111:1-6. https://doi.org/10.14411/eje. 2014.082

Fukuda S, Konuma J (2019) Using three-dimensional printed models to test for aposematism in a carabid beetle. Biol J Linn Soc 128:735741. https://doi.org/10.1093/biolinnean/blz127

Grüm L (1971a) Remarks on the differentiation in Carabidae mobility. Ekologia Polska 19:47-56

Grüm L (1971b) Spatial differentiation of the Carabus L. (Carabidae, Coleoptera) mobility. Ekologia Polska 19:1-34

Hüppop O, Ciach M, Diehl R, Reynolds DR, Stepanian PM, Menz MHM (2020) Perspectives and challenges for the use of radar in biological conservation. Ecography 42:912-930. https://doi.org/10.1111/ecog. 04063

Kareiva P, Shigesada N (1983) Analyzing insect movement as a correlated random walk. Oecologia 56:234-238. https://doi.org/10.1007/ BF00379695

Kissling DW, Pattemore DE, Hagen M (2014) Challenges and prospects in the telemetry of insects. Biol Rev 83:511-530. https://doi.org/10. 1111/brv. 12065

Koivula MJ, Venn S, Hakola P, Niemelä J (2019) Responses of boreal ground beetles (Coleoptera, Carabidae) to different logging regimes ten years post harvest. For Ecol Manage 436:27-38. https://doi.org/ 10.1016/j.foreco.2018.12.047

Kuuluvainen T, Tahvonen O, Aakala T (2012) Even-aged and unevenaged forest management in boreal Fennoscandia: A review. Ambio 41:720-737. https://doi.org/10.1007/s13280-012-0289-y

Langrock R, King R, Matthiopoulos J, Thomas L, Fortin D, Morales JM (2012) Flexible and practical modeling of animal telemetry data: Hidden Markov models and extensions. Ecology 93:2336-2342. https://doi.org/10.1890/11-2241.1

Liégeois M, Tixier P, Beaudoin-Ollivier L (2016) Use of radio telemetry for studying flight movements of Paysandisia archon (Lepidoptera: Castniidae). J Insect Behav 29:199-213

Lindenmayer DB, Likens GE, Andersen A, Bowman D, Bull CM, Burns E, Dickman CR, Hoffmann AA, Keith DA, Liddell MJ, Lowe AJ, Metcalfe DJ, Phinn SR, Russell-Smith J, Thurgate N, Wardle GM (2012) Value of long-term ecological studies. Austral Ecol 37:745757. https://doi.org/10.1111/j.1442-9993.2011.02351.x

Lövei GL, Sunderland KD (1996) Ecology and behavior of ground beetles (Coleoptera: Carabidae). Annu Rev Entomol 41:231-256. https://doi.org/10.1146/annurev.en.41.010196.001311

Makowski D, Ben-Shachar M, Lüdecke D (2019) bayestestR: Describing effects and their uncertainty, existence and significance within the Bayesian framework. J Open Source Softw 4:1541. https://doi.org/ 10.21105/joss.01541

McClintock BT, Langrock R, Gimenez O, Cam E, Borchers DL, Glennie R, Patterson TA (2020) Uncovering ecological state dynamics with hidden Markov models. Ecol Lett 23:1878-1903. https://doi.org/10. 1111/ele.13610

Michelot T, Langrock R, Patterson TA (2016) moveHMM: an R package for the statistical modelling of animal movement data using hidden Markov models. Methods Ecol Evol 7:1308-1315. https://doi.org/ 10.1111/2041-210X.12578

Morey RD, Rouder JN (2018) BayesFactor: Computation of bayes factors for common designs. R package version 0.9.12-4.2. https:// CRAN.R-project.org/package=BayesFactor. Accessed 18 Dec 2020

Mori AS, Kitagawa R (2014) Retention forestry as a major paradigm for safeguarding forest biodiversity in productive landscapes: A global meta-analysis. Biol Conserv 175:65-73. https://doi.org/10.1016/j. biocon.2014.04.016

Negro MA, Casale AC, Migliore LUCA, Palestrini CL, Rolando AN (2008) Habitat use and movement patterns in the endangered ground 
beetle species, Carabus olympiae (Coleoptera: Carabidae). Eur J Entomol 105:105-112. https://doi.org/10.14411/eje.2008.015

Negro M, Caprio E, Leo K, Maritano U, Roggero A, Vacchiano G, Palestrini C, Rolando A (2017) The effect of forest management on endangered insects assessed by radio-tracking: The case of the ground beetle Carabus olympiae in European beech Fagus sylvatica stands. For Ecol Manage 406:125-137. https://doi.org/10.1016/j. foreco.2017.09.065

Niemelä J, Koivula M, Kotze DJ (2007) The effects of forestry on carabid beetles (Coleoptera: Carabidae) in boreal forests. J Insect Conserv 11:5-18. https://doi.org/10.1007/s10841-006-9014-0

Paillet Y, Archaux F, du Puy S, Bouget C, Boulanger V, Debaive N, Gilg O, Gosselin F, Guilbert E (2018) The indicator side of tree microhabitats: A multi-taxon approach based on bats, birds and saproxylic beetles. J Appl Ecol 55:2147-2159. https://doi.org/10.1111/13652664.13181

Parsons PA (1992) Fluctuating asymmetry: A biological monitor of environmental and genomic stress. Heredity 68:361-364. https://doi. org/10.1038/hdy.1992.51

Patterson TA, Parton A, Langrock R, Blackwell PG, Thomas L, King R (2017) Statistical modeling of individual animal movement: an overview of key methods and a discussion of practical challenges. Adv Stat Anal 101:399-438. https://doi.org/10.1007/s10182-017-0302-7

Pommerening A, Murphy ST (2004) A review of the history, definitions and methods of continuous cover forestry with special attention to afforestation and restocking. Forestry 77:27-44. https://doi.org/10. 1093/forestry/77.1.27

R Core Team (2020) R: A language and environment for statistical computing, version: 3.6.3. R Foundation for Statistical Computing, Vienna. https://www.R-project.org/. Accessed 18 Dec 2020

Raftery AE (1995) Bayesian model selection in social research. Sociol Methodol 25:111-163. https://doi.org/10.2307/271063
Riecken U, Raths U (1996) Use of radio telemetry for studying dispersal and habitat use of Carabus coriaceus L. Annal Zool Fenn 33:109116

Růžičková J, Veselý M (2016) Using radio telemetry to track ground beetles: Movement of Carabus ullrichii. Biologia 71:924-930. https://doi.org/10.1515/biolog-2016-0108

Růžičková J, Veselý M (2018) Movement activity and habitat use of Carabus ullrichii (Coleoptera: Carabidae): The forest edge as a mating site? Entomol Sci 21:76-83. https://doi.org/10.1111/ens.12286

Růžičková J, Bérces S, Ackov S, Elek Z (2021) Individual movement of large carabids as a link for activity density patterns in various forestry treatments. Acta Zool Acad Sci Hung 67:77-86. https://doi. org/10.17109/AZH.67.1.77.2021

Spake R, Barsoum N, Newton AC, Doncaster CP (2016) Drivers of the composition and diversity of carabid functional traits in UK coniferous plantations. For Ecol Manage 359:300-308. https://doi.org/ 10.1016/j.foreco.2015.10.008

Thiele HU (1977) Carabid beetles in their environments. Springer, Berlin, 369 pp. https://doi.org/10.1007/978-3-642-81154-8

Turchin P, Odendaal FJ, Rausher MD (1991) Quantifying insect movement in the field. Environ Entomol 20:955-963. https://doi.org/10. 1093/ee/20.4.955

Vinatier F, Chailleux A, Duyck PF, Salmon F, Lescourret F, Tixier P (2010) Radiotelemetry unravels movements of a walking insect species in heterogeneous environments. Anim Behav 80:221-229. https://doi.org/10.1016/j.anbehav.2010.04.022

Wallin H, Ekbom BS (1988) Movements of carabid beetles (Coleoptera: Carabidae) inhabiting cereal fields: a field tracing study. Oecologia 77:39-43. https://doi.org/10.1007/BF00380922

Publisher's Note Springer Nature remains neutral with regard to jurisdictional claims in published maps and institutional affiliations. 